\title{
Pengaruh Komitmen Organisasi Terhadap Sistem Informasi Keuangan
}

\author{
Lesi Hertati', Irlan Fery ${ }^{2}$, Otniel Safkaur ${ }^{3}$ \\ 1, 2 STIE Rahmaniyah, ${ }^{3}$ Universitas Cendrawasih \\ 1hertatilesi@yahoo.co.id
}

\begin{abstract}
The complexity of the financial information system process requires obeying the Indonesian financial accounting standard regulatory procedures in carrying out financial information, as well as demanding that individuals implementing financial information systems have strong working power that is safe and sustainable in order to run a good financial information system process. The purpose of this study is to determine the effect of organizational commitment to financial information systems, on state-owned enterprises in South Sumatra. This research is a quantitative method research with a total sample of 48 BUMN spread across South Sumatra. The analytical tool used is multiple regression with SPSS version 24. The results show that organizational commitment influences financial information systems.
\end{abstract}

Keywords: Organizational Commitment, Financial Information Systems

\begin{abstract}
Abstrak
Kompleksitas proses sistem informasi keuangan mengharuskan taat pada prosedur peraturan standar akuntansi keuangan Indonesia dalam menjalankan informasi keuangan, serta menuntut individuindividu pelaksana sistem informasi keuangan memiliki daya bekerja yang kuat skiil yang mempuni dan berkesinambungan guna menjalankan proses sistem informasi keuangan yang baik. Tujuan dari penelitian ini adalah mengetahui pengaruh komitmen organisasi terhadap sistem informasi keuangan, pada badan usaha milik negara di Sumatera Selatan. Penelitian ini merupakan penelitian dengan metode kuantitatif dengan total sampel sebanyak 48 BUMN yang tersebar di Sumatera Selatan. Alat analisis yang digunakan adalah regresi berganda dengan alat bantu SPSS versi 24. Hasil penelitian menunjukkan bahwa komitmen organisasi berpengaruh terhadap sistem informasi keuangan.
\end{abstract}

Kata Kunci: Komitmen Organisasi, Sistem Informasi Keuangan 


\section{PENDAHULUAN}

Badan Usaha Milik Negara berdiri memiliki peran strategis yang sangat dibutuhkan oleh masyarakat. Ada lima faktor yang menjadi latar belakang pendirian BUMN, yaitu: (1) Sebagai pelopor atau perintis usaha dimana swasta tidak tertarik untuk memasukinya; (2) Sebagai pengelola bidang usaha strategis dan pelaksana pelayanan publik; (3) Sebagai penyeimbang bagi kekuatan swasta besar; (4) Sebagai sumber pendapatan negara; dan (5) Sebagai hasil nasionalisasi Perusahaan Belanda. Tujuan BUMN adalah: (1) Memberikan sumbangan bagi perkembangan perekonomian nasional pada umumnya; (2) Mengejar keuntungan; (3) Menyelenggarakan kebermanfaatan umum berupa penyediaan barang dan/ atau jasa yang bermutu tinggi dan memadai bagi pemenuhan hajat hidup orang banyak; (4) Menjadi perintis kegiatan usaha yang belum dapat dilaksanakan oleh sektor swasta dan koperasi; dan (5) Turut aktif memberikan bimbingan dan bantuan kepada pengusaha golongan ekonomi lemah, koperasi, dan masyarakat.Pengelola bidang usaha strategis baik atau buruknya BUMN sebagai sumber pendapatan negara bekerja melayani kebutuhan public dapat dilihat dari laporan keuangan yang menyediakan informasi keuangan perusahaan dan bermanfaat bagi pengguna laporan dalam pengambilan keputusan (Hertati, 2019).

Fokus utama para pengguna laporan keuangan adalah informasi tentang kinerja perusahaan yang diukur oleh laba dan komponen-komponennya. Para investor dan kreditor sebagai pengguna laporan keuangan menggunakan informasi laba masa lalu untuk membantu menilai prospek perusahaan. Laba yang dilaporkan perusahaan mengandung ketidakjelasan atau ketidaktransparanan antara laba akuntansi yang dapat diobservasi dan laba ekonomi yang tidak dapat diobservasi, disebut earning opacity. Laba yang dilaporkan perusahaan mungkin menjadi tidak jelas karena adanya interaksi yang kompleks antara, motivasi manajerial, standar akuntansi, dan pelaksanaan standar akuntansi. Para manajer memiliki dorongan untuk mengelola laporan laba perusahaan dengan menggunakan kebijakan akrual yang diijinkan oleh standar akuntansi dengan tujuan untuk menutupi kinerja perusahaan yang sebenarnya, misalnya melaporkan laba lebih tinggi dan menyembunyikan realisasi laba yang tidak menguntungkan (kerugian) yang dapat memicu campur tangan pihak lain.

Sebagai agen pembangunan (agent of development) telah terjadi kemajuan dalam pengelolaan BUMN di Indonesia beberapa tahun terakhir ini. Sofyan Djalil (2008) mengatakan bahwa dalam kurun waktu 2004 sampai tahun 2007 terjadi pertumbuhan signifikan pada penjualan (pendapatan) dan aset BUMN. Pada tahun 2004 total penjualan (pendapatan) seluruh BUMN berjumlah Rp 520 triliun, kemudian meningkat menjadi Rp 654 triliun pada tahun 2005, menjadi Rp 763 triliun pada tahun 2006, dan menjadi Rp 889 pada tahun 2007. Begitu juga dengan total aset, pada tahun 2004 total aset seluruh BUMN berjumlah Rp 1.247 triliun, kemudian meningkat menjadi Rp 1.366 triliun pada tahun 2005, menjadi Rp 1.506 pada tahun 2006, dan menjadi Rp 1.719 pada tahun 2007.

PT. Telkom Tbk. dan PT. Aneka Tambang Tbk. Lebih lanjut Sri Mulyani (2010) mengatakan bahwa setiap tahun Departemen Keuangan memberikan penghargaan kepada BUMN yang memiliki prestasi dalam penyusunan laporan keuangan, namun yang mendapat 
penghargaan dari tahun ke tahun hanya BUMN tertentu saja, sementara ada ratusan BUMN lain di Indonesia yang tidak mengalami perbaikan dari tahun ke tahun dalam proses pembuatan laporan keuangan sesuai standar akuntansi keuangan yang berlaku. Laporan keuangan BUMN juga menunjukkan angka-angka yang tidak akurat dan diragukan kebenarannya. Berdasarkan Laporan Keuangan Pemerintah Pusat Tahun 2008 yang memuat laporan keuangan seluruh BUMN di Indonesia, terlihat ada 11 BUMN yang melaporkan saldo ekuitas bernilai negatif. Ekuitas merupakan sisa bagian pemilik atas klaim aset yang secara teknis dihitung dengan mengurangkan antara aset dan kewajiban. Secara teori saldo ekuitas tidak mungkin bernilai negarif karena hal itu berarti bahwa modal perusahaan sudah tidak ada lagi dan secara teknis perusahaan harus dibubarkan. Bila di lihat dari proses sistem informasi akuntansi, ekuitas bersaldo negatif dapat disebabkan oleh sistem informasi akuntansi yang tidak akurat dalam pencatatan transaksi akuntansi keuangan BUMN yang memiliki saldo ekuitas negatif pada Laporan Keuangan Tahun 2008.

Laporan keuangan yang baik sesuai dengan standar pelaporan yang berlaku adalah mengumpulkan, mencatat, menyimpan, dan memproses data untuk menghasilkan dihasilkan oleh sebuah proses sistem informasi keuangan yang baik sistem informasi keuangan adalah sebuah sistem yang informasi untuk tujuan pengambilan keputusan. Sistem Informasi keuangan merupakan sub sistem dari sistem informasi manajemen, yang mengumpulkan, memproses, dan melaporkan informasi yang berhubungan dengan transaksi keuangan.Sistem informasi keuangan adalah kumpulan dari subsistem-subsistem yang saling berhubungan satu sama lain dan bekerja sama secara harmonis untuk mengolah data keuangan menjadi informasi keuangan yang diperlukan oleh manajemen dalam proses pengambilan keputusan dibidang keuangan. Sistem informasi keuangan merupakan bagian terpenting dari sistem informasi manajemen, dan merupakan integrasi dari berbagai sistem pengolahan transaksi yang bekerja di berbagai fungsi operasional organisasi (Romney and Steinbart, 2009: Susanto, 2014: Gelinas et.al, 1993).

Sebagai sebuah sistem yang tersusun oleh banyak komponen seperti orang, aktivitas, data, perangkat keras, perangkat lunak, dan jaringan, sistem informasi keuangan dalam penerapannya rentan terhadap masalah dan kegagalan. Keberhasilan penerapan sistem informasi keuangan di perusahaan tidaklah mudah untuk dicapai dan seringkali menimbulkan masalah karena dipengaruhi oleh banyak faktor, antara lain: (1) Keterlibatan pemakai; (2) Dukungan pimpinan; (3) Pelatihan dan pendidikan pemakai; (4) Faktor kelompok kerja dalam organisasi; dan (5) Faktor organisasi lainnya seperti ukuran organisasi, kharakteristik tugas, dan lain-lain. Disamping faktor organisasi seperti kompleksitas tugas, ukuran organisasi, faktor kepemimpinan, dan lain-lain, faktor individual seperti motivasi, kepuasan, dan kebermanfaatan bagi pemakai sangat menentukan keberhasilan penerapan sistem informasi keuangan. Keberhasilan penerapan informasi keuangan adalah masalah krusial diperusahaan, karena ditentukan oleh faktor situasi dan kondisi dimana sistem informasi keuangan tersebut diterapkan, antara lain berkaitan erat dengan: (1) Faktor lingkungan perusahaan; (2) Isi (content) sistem informasi keuangan yang digunakan, seperti tugas, struktur, teknologi, dan orang; dan (3) Proses penerapan sistem informasi keuangan (Choe, 1996; Burton, et.al, 1992; Kaye, 2001; Hertati, 2015). 
Masalah keangenan terjadi antara principals dan agents yang menyebabkan kemungkinan agen bertindak tidak sesuai dengan kepentingan principals. Untuk mengurangi tindakan manajemen yang tidak sesuai dengan harapan prinsipal diperlukan komitmen organisasi dengan meningkatkan sistem informasi keuangan yang berperan sebagai transparan dalam pelaporan keuangan. Peran komitmen manajemen sebagai keyakinan bahwa usaha akan menghasilkan kinerja seperti seorang yang bekerja keras akan mendapatkan kinerja yang baik, dengan asumsi bahwa seorang tersebut: (1) Memiliki sumber daya yang cukup; (2) Memiliki keahlian (skill) yang mendukung pekerjaan; dan (3) Ada dukungan (support) dalam melakukan pekerjaan. Keyakinan apabila seseorang melakukan sesuatu dengan baik atau memiliki kinerja yang baik maka akan mendapatkan value outcome yang baik pula, seperti bila seorang bekerja dengan baik maka akan mendapatkan kebaikan bagi dirinya, dengan asumsi bahwa: (1) Ada pemahaman tentang hubungan antara kinerja dan hasil (reward system); (2) Ada keyakinan bahwa ketika suatu keputusan diambil akan diperoleh hasil atas keputusan tersebut; dan (3) Ada transparansi proses antara apa yang didapat dan apa yang dihasilkan. Valensi adalah harapan seseorang atas sebuah dampak hasil (outcome), seperti seseorang yang memiliki harapan untuk mendapatkan sejumlah uang atau penghargaan lainnya.

Komitmen organisasi merupakan keadaan emosi karyawan untuk mengidentifikasi dan terlibat dengan organisasi. Komitmen organisasi melibatkan tiga sikap, yaitu: (1) Adanya identifikasi seseorang terhadap tujuan organisasi; (2) Adanya keterlibatan dalam tugas-tugas organisasi; dan (3) Adanya loyalitas terhadap organisasi. penelitian ini defenisi komitmen organisasional merujuk kepada komitmen organisasional adalah sikap identifikasi, keterlibatan, dan loyalitas seorang karyawan terhadap perusahaan (Mowday, et.al., 1982; McShane and Von Glinow, 2000; Gibson, et. al, 1994; Hertati, 2015). Dimensi yang mendominasi operasionalisasi konsep komitmen organisasi meliputi tiga hal: 1). Identifikasi (identification), yaitu kepercayaan yang kuat dan penerimaan karyawan atas tujuan dan nilai organisasi; 2). Keterlibatan (involvement), yaitu kemauan karyawan untuk memberikan usaha demi kepentingan organisasi; 3). Loyalitas (loyality), yaitu keinginan dan hasrat yang kuat karyawan untuk selalu menjaga keanggotaan organisasi.

Komitmen organiasi berhubungan dengan sistem informasi direpresentasi yaitu: (1) system characteristic (F1); (2) Quality (F2); (3) Outcome (F3 \& F5); dan (4) User Requerement (F4). System characteristic (F1) mencerminkan tiga fungsi yang dibutuhkan oleh sebuah sistem yaitu penyimpanan (storage), proses (processing), dan komunikasi (communications), dan biaya (cost) yang dikeluarkan sistem untuk tiga fungsi ini adalah representasi dari kharakteristik sistem. Quality (F2) adalah kualitas dari sebuah sistem yang digunakan. Sementara itu Outcome terbagi atas internal outcome (F3) dan external outcome (F5). Sebuah sistem informasi secara Internal outcome (F3) diharapkan menghasilkan informasi yang akurat dan lengkap tentang sebuah transaksi, sedangkan sistem informasi secara external outcome dapat meningkatkan image perusahaan dan layanan terhadap pelanggan. Sedangkan User requirement (F4) adalah terfokus kepada keterlibatan dan partisipasi pemakai terhadap sistem informasi (Hertati, 2016; Choe, 1996; Burton, et.al, 1992; Kaye, 2001; Lee, J.J., and Kim, S.H., 1992; Livari, J., 2005). Sistem informasi keuangan 
dapat dikelompokkan atas tiga aspek utama, yaitu: 1) Kualitas sistem, 2) Pengguna sistem; 3) Pengguna informasi.

\section{METODE}

Lokasi penelitian ini bertempat di Sumatera Selatan populasi yaitu unit-unit fungsional pada BUMN di Sumatera Selatan. Jumlah populasi dalam penelitian ini berjumlah 45 Sampel diambil dengan menggunakan rumus slovin dengan tingkat kesalahan 5\% dengan jumlah sampel sebanyak 200 responden. Dari kuesioner yang disebar sebanyak 200, yang kembali adalah sebanyak 105 dan yang dapat diproses sebnyak 102 kuesioner, sebanyak 3 responden mengisi tidak lengkap. Penelitian ini menggunakan metode kuantitatif dengan alat analisis regresi berganda. Skala yang digunakan menggunakan skala likert lima poin. Variabel independen dalam penelitian ini adalah komitmen orgnaisasi $\left(\mathrm{X}_{1}\right)$, dan sistem informasi keuangan $(\mathrm{Y})$ sebagai variabel dependennya. Hubungan variabel-variabel tersebut dapat digambarkan secara sistematis sebagai berikut:

$$
\mathrm{Y}=\mathrm{f}\left(\mathrm{X}_{1}\right)
$$

Tabel berikut menunjukkan variabel dimensi dan indikator dalam penelitian ini:

Tabel 1. Variabel Dimensi dan Indikator

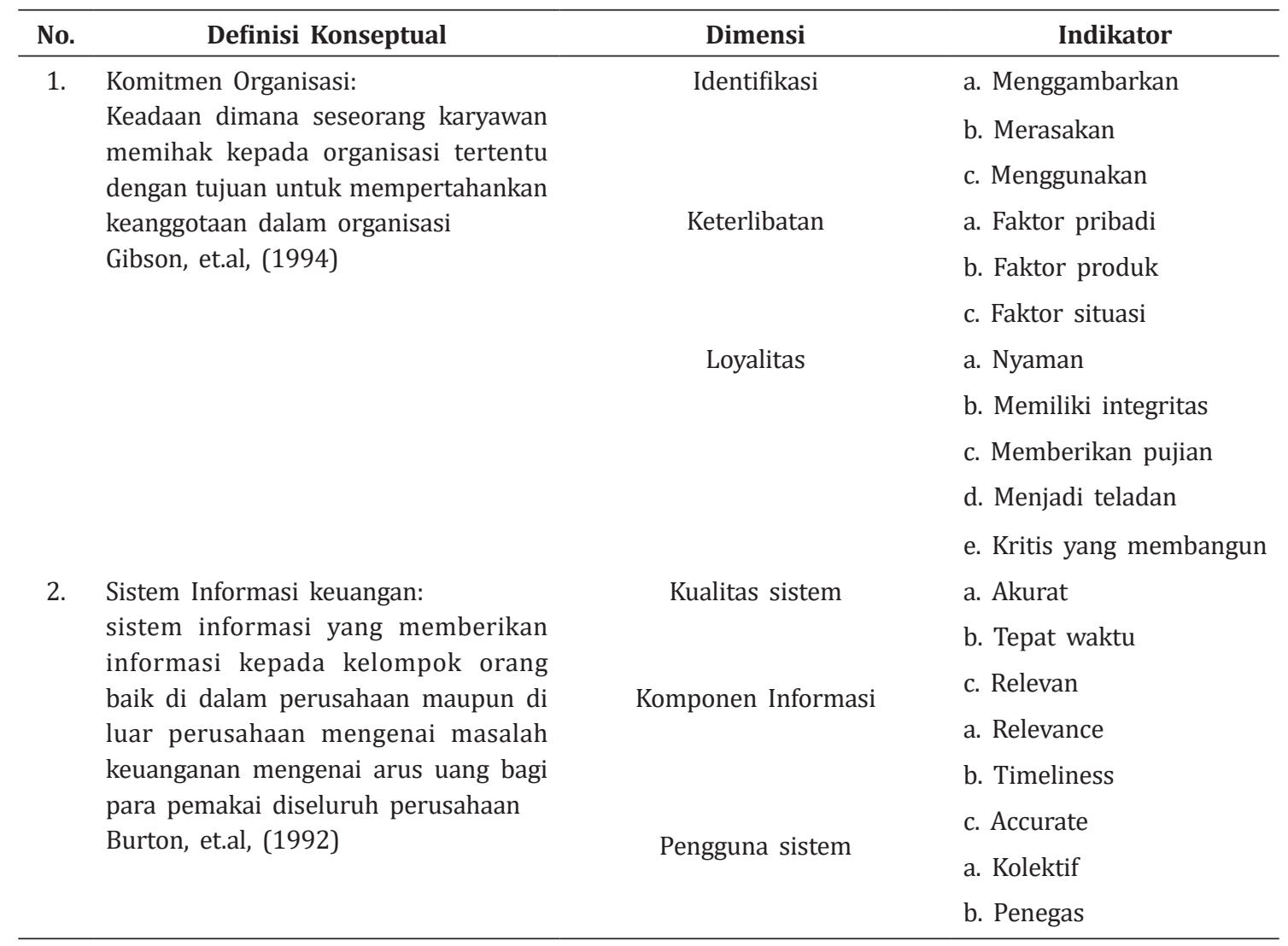

Sumber: Hasil dan Pembahasan Variabel Dimensi dan Indikator, 2020 


\section{HASIL DAN PEMBAHASAN}

Hasil uji validitas dan reliabilitas dapat dilihat pada Tabel 2 dan Tabel 3 berikut:

Tabel 2. Hasil Uji Validitas

\begin{tabular}{|c|c|c|c|c|}
\hline Variabel & Indikator & Nilai $\mathbf{r}$ & Signifikansi & Keterangan \\
\hline \multirow{11}{*}{ Komitmen Organisasi } & $\mathrm{X} 1$ & $.624^{* *}$ & .000 & Valid \\
\hline & $\mathrm{X} 2$ & $.806^{* *}$ & .000 & Valid \\
\hline & $\mathrm{X} 3$ & $.754^{* *}$ & .000 & Valid \\
\hline & $\mathrm{X} 4$ & $.833^{* *}$ & .000 & Valid \\
\hline & $\mathrm{X} 5$ & $.731^{* *}$ & .000 & Valid \\
\hline & $\mathrm{X} 6$ & $.787^{* *}$ & .000 & Valid \\
\hline & $\mathrm{X} 7$ & $.815^{* *}$ & .000 & Valid \\
\hline & $\mathrm{X} 8$ & $.765^{* *}$ & .000 & Valid \\
\hline & X9 & $.880^{* *}$ & .000 & Valid \\
\hline & $\mathrm{X} 10$ & $.804^{* *}$ & .000 & Valid \\
\hline & $\mathrm{X} 11$ & $.788^{* *}$ & .000 & Valid \\
\hline \multirow{8}{*}{ Sistem Informasi Keuangan } & $\mathrm{X} 12$ & $.860^{* *}$ & .000 & Valid \\
\hline & $\mathrm{X} 13$ & $.865^{* *}$ & .000 & Valid \\
\hline & $\mathrm{X} 14$ & $.853^{* *}$ & .000 & Valid \\
\hline & $\mathrm{X} 15$ & $.749^{* *}$ & .000 & Valid \\
\hline & $\mathrm{X} 16$ & $.855^{* *}$ & .000 & Valid \\
\hline & $\mathrm{X} 17$ & $.968^{* *}$ & .000 & Valid \\
\hline & X18 & $.849^{* *}$ & .000 & Valid \\
\hline & X19 & $.619^{* *}$ & .000 & Valid \\
\hline
\end{tabular}

Sumber: Data primer diolah, 2020

Tabel 3. Hasil Uji Reliabilitas

\begin{tabular}{cccc}
\hline No & Variabel Laten & Cronbach's Alpha & Keterangan \\
\hline 1 & Identifikasi & .943 & Reliabel \\
2 & Keterlibatan & .847 & Reliabel \\
3 & Loyalitas & .861 & Reliabel \\
\hline
\end{tabular}

Sumber: Data primer diolah, 2020

Berdasarkan data pada tabel 2 dan tabel 3 menunjukkan bahwa pernyataan dalam kuesioner penelitian ini adalah valid dan reliabel. 
Sementara itu, hasil uji t dan uji $\mathrm{F}$ ditunjukkan pada tabel 4 dan tabel 5:

Tabel 4. Hasil Uji t

\begin{tabular}{|c|c|c|c|c|c|c|}
\hline & \multirow[t]{2}{*}{ Model } & \multicolumn{2}{|c|}{$\begin{array}{c}\text { Unstandardized } \\
\text { Coefficients }\end{array}$} & \multirow{2}{*}{$\begin{array}{c}\text { Standardized } \\
\text { Coefficients }\end{array}$} & \multirow[t]{2}{*}{$\mathbf{T}$} & \multirow[t]{2}{*}{ Sig. } \\
\hline & & B & Std. Error & & & \\
\hline \multirow[t]{4}{*}{1} & (Constant) & 11.575 & 4.744 & & 2.440 & .000 \\
\hline & Komitmen Organisasi & 1.239 & 4.162 & .182 & 4.010 & .000 \\
\hline & Sistem Informasi Keuangan & 1.186 & .230 & .635 & 4.154 & .000 \\
\hline & Nilai $r$ square: 0,636 & & & & & \\
\hline
\end{tabular}

Sumber: Data primer diolah, 2020

Tabel 5. Hasil Uji F

\begin{tabular}{llccccc}
\hline \multicolumn{1}{c}{ Model } & Sum of Squares & Df & Mean Square & F & Sig. \\
\hline \multirow{2}{*}{1} & Regression & 16358.509 & 2 & 8179.255 & 83.133 & $.000^{\mathrm{a}}$ \\
\cline { 3 - 5 } & Residual & 9346.838 & 95 & 98.388 & & \\
\cline { 2 - 4 } & Total & 25705.347 & 97 & & & \\
\hline
\end{tabular}

Sumber: Data primer diolah, 2019

Berdasarkan data yang diperoleh pada Tabel 4, diketahui bahwa nilat hitung variabel $\mathrm{t}$ hitung variabel komitman organisasi $>$ nilai t tabel, yaitu 4,010 $>1,985$, hasil ini menunjukkan bahwa komitmen organisasi berpengaruh pada sistem informasi keuangan BUMN di Sumatera Selatan. Nilai R square diperoleh 0,636 atau 63,6\% yang mengartikan persentase sumbangan pengaruh variabel independen terhadap variabel dependen sebesar 63,6\%. Hasil uji $\mathrm{F}$ pada Tabel 5 menunjukkan bahwa model yang digunakan dalam penelitian ini sudah fit.

Untuk mengetahui hubungan antar dimensi dari masing-masing variabel, dibuat perhitungan korelasi antar dimensi. Korelasi antar dimensi dapat dilihat pada Tabel 6.

Tabel 6. Korelasi Antar Dimensi

\begin{tabular}{lllll}
\hline & \multicolumn{1}{c}{ Dimensi } & Y1.1 & Y1.2 & Y1.3 \\
\hline X1.1 & Identifikasi & $.684^{* *}$ & $.681^{* *}$ & $.711^{* *}$ \\
X1.2 & Keterlibatan & $.637^{* *}$ & $.657^{* *}$ & $.679^{* *}$ \\
X1.3 & Loyalitas & $.760^{* *}$ & $.763^{* *}$ & $.792^{* *}$ \\
\hline Y1.1 & Kualitas sistem & 1 & $.792^{* *}$ & $.940^{* *}$ \\
Y1.2 & Pengguna Sistem & $.792^{* *}$ & 1 & $.986^{* *}$ \\
Y1.3 & Pengguna informasi & $.840^{* *}$ & $.986^{* *}$ & 1 \\
\hline
\end{tabular}

Sumber: Data primer diolah, 2019

Berdasarkan hasil olah data pada Tabel 6, dapat dilihat bahwa masing-masing variabel antar dimensi memiliki hubungan yang cukup kuat. Tabel 6 memperlihatkan bahwa korelasi antara dimensi keterlibatan memiliki hubungan yang paling kuat dengan dimensi faktor utama dalam bekerja, serta dimensi loyalinas memiliki hubungan yang paling kuat dengan dimensi 
yang sama, yakni faktor utama dalam bekerja. Serta Dimensi penggunaan sistem memiliki hubungan yang kuat dengan dimensi kualitas sistem yakni factor penggunaan informasi.

Temuan ini konsisten dengan penelitian yang dilakukan Etty Murwaningsari (2008) dan Torkzadeh \& Doll (1998) melakukan penelitian tentang hubungan antara interaksi keterlibatan kerja dan komitmen organisasi terhadap kinerja tugas. Dari hasil survei terhadap 532 orang akademisi dan tenaga teknik pada empat perusahaan penelitian dan pengembangan (R\&D), disimpulkan bahwa ada hubungan interaksi antara keterlibatan kerja dan komitmen organisasi terhadap kinerja tugas. Lee and Kim (1992) dan (Shirani, et.al. 1994) melakukan penelitian tentang hubungan antara komitmen organisasi, terhadap sistem informasi keuangan. Dari hasil survei terhadap 929 karyawan dari 57 perusahaan jasa dan manufaktur kecil dan menengah di Cina, Livari (2005) menemukan bahwa komitmen organisasi berhubungan signifikan dengan sistem informasi keuangan. Clercq and Rius (2007) dan Shirani, et.al. (1994) melakukan penelitian tentang hubungan antara komitmen organisasi, dan usaha (effort). Dari hasil survei terhadap 863 karyawan dari berbagai perusahaan kecil dan menengah di Meksiko, Clercq and Rius (2007) menyimpulkan bahwa komitmen organisasi berhubungan secara signifikan terhadap usaha (effort). Kemudian Etty (2008) melakukan penelitian tentang pengaruh moderasi komitmen organisasi dan keadilan prosedural, terhadap hubungan antara partisipasi anggaran dan kinerja manajerial. Dari hasil survei terhadap 32 manajer berbagai perusahaan di Indonesia, disimpulkan bahwa komitmen organisasi adalah variabel pemoderasi yang memperkuat hubungan antara partisipasi anggaran dan kinerja manajerial.

Penelitian Burton et.al. (1992) dan Yuksel (2004) secara intrinsik berdasarkan teori ekspektasi seorang pengguna sistem informasi akuntansi akan selalu mengevaluasi dampak dari penggunaan sistem informasi akuntansi, seperti peningkatan efisiensi dan efektivitas pengambilan keputusan, frekwensi ketepatan dalam pengambilan keputusan, dan peningkatan pemahaman atas pekerjaan. Evaluasi intrinsik atas dampak penggunaan sistem informasi akuntansi selanjutnya akan menjadi sumber motivasi bagi pengguna sistem informasi akuntansi. Penelitian Burton, et.al. (1992) dan Zhang, (2005) disamping faktor organisasi seperti kompleksitas tugas, ukuran organisasi, faktor kepemimpinan, dan lainlain, faktor individual seperti motivasi, kepuasan, dan kebermanfaatan bagi pemakai sangat menentukan keberhasilan penerapan sistem informasi keuangan. Penelitian Kaye (2001), keberhasilan penerapan sistem informasi keuangan adalah masalah krusial diperusahaan, karena ditentukan oleh faktor situasi dan kondisi dimana sistem informasi keuangan tersebut diterapkan, antara lain berkaitan erat dengan: (1) Faktor lingkungan perusahaan; (2) Isi (content) sistem informasi keuangan yang digunakan, seperti tugas, struktur, teknologi, dan orang; dan (3) Proses penerapan sistem informasi keuangan.

Chen, et.al (2002), menyatakan bahwa komitmen organisasi adalah ikatan psikologi seorang karyawan terhadap perusahaan yang mendorong karyawan tersebut bekerja keras mencapai tujuan perusahaan. Mowday, et.al. (1982) memberikan arti yang lebih orisinil tentang komitmen organisasional, bahwa komitmen organisasional memiliki tiga komponen utama: (1) Penerimaan atas nilai dan tujuan perusahaan; (2) Mendahulukan kepentingan perusahaan; dan (3) Keinginan untuk tetap menjadi karyawan dari sebuah 
perusahaan. Kemudian Haar Spell (2004) menjelaskan bahwa komitmen organisasional secara konseptual merupakan pola perilaku, intensitas, motivasi, dan sikap yang ada dalam diri seseorang. Tingkat komitmen organisasi yang di miliki manajer dan karyawan dapat mendorong keberhasilan penerapan sistem informasi keuangan di perusahaan, sebagaimana penelitian yang dilakukan oleh Livari (2005) dan Zhang (2007a) bahwa dari sekian banyak faktor yang mempengaruhi keberhasilan penerapan sistem informasi keuangan, komitmen organisasi adalah faktor utama dan sangat penting, karena inti dari komitmen organisasi adalah keterikatan dan loyalitas seorang karyawan kepada perusahaan yang akan mendorong mereka untuk selalu bekerja dalam berbagai situasi di perusahaan. Kemudian Penelitian Thong (1996) dan Zhang (2007b) mengatakan bahwa komitmen organisasi sebagai faktor organisasi yang sangat penting untuk keberhasilan penerapan sistem informasi keuangan disamping faktor lain seperti: integrasi SIK dengan perencanaan perusahaan, kualitas output SIK, efisiensi operasi SIK, sikap pemakai/manajemen.

Penelitian Cerullo (1997) dan Neely (1995) komitmen organisasi mempengaruhi keberhasilan penerapan sistem informasi keuangan antara lain melalui: (1) Penetapan tujuan dan penilaian objektif perusahaan dalam penerapan sistem informasi keuangan; (2) Evaluasi proposal proyek sistem informasi keuangan yang objektif; (3) Pendefenisian informasi dan proses yang dibutuhkan; dan (4) Review program dan rencana untuk pengembangan sistem informasi keuangan. Penelitian Lee and Kim (1992) dan Saunders, \& Jones (1992) mengatakan bahwa komitmen organisasi mempengaruhi keberhasilan penerapan sistem informasi keuangan melalui upaya formalisasi pengembangan sistem informasi keuangan di perusahaan. Dengan formalisasi pengembangan sistem informasi keuangan kelemahan dalam pengalaman dan pembelajaran personal pengguna menjadi dapat diatasi.

\section{SIMPULAN}

Berdasarkan penelitian yang telah dilakukan mengenai pengaruh komitmen organisasi terhadap sistem informasi keuangan. Penelitian ini membuktikan bahwa komitmen organisasi berpengaruh terhadap sistem informasi keuangan telah sesuai dengan teori keagenan, dimana perusahaan dengan kepemilikan institusional, kepemilikan managerial pengaruh komitmen organisasi terhadap sistem informasi keuangan baik secara parsial maupun simultan. Keberhasilan sistem informasi keuangan dapat dicapai dengan optimalisasi dengan meningkatan komitmen organisasi. Komitmen organisasi berpengaruh terhadap sistem informasi keuangan secara simultan berdampak positif diduga karena: (1) Sangat kompleksnya faktor yang mempengaruhi informasi Keuangan (ROE); dan (2) informasi keuangan sebagai alat bantu untuk menghasilkan informasi keuangan melalui faktor-faktor lain seperti proses pengambilan keputusan, kualitas keputusan, dinamisasi individu dalam organisasi, efisiensi dan efektivitas, dan lain-lain. Sistem Informasi keuangan perusahaan adalah tingkat prestasi atau keberhasilan keuangan yang dicapai oleh suatu perusahaan pada suatu periode tertentu. Tingkat prestasi atau keberhasilan keuangan biasanya dikaitkan dengan tingkat laba yang diperoleh oleh perusahaan. sistem Informasi keuangan datanya bersumber dari laporan keuangan, karena menyajikan data masa lalu dan tidak berorientasi ke depan sehingga dianggap kurang relevan dengan keadaan saat ini. 
Atas dasar pemikiran ini maka lahirlah konsep pengukuran kinerja non tradisional, yang dikenal dengan pengukuran kinerja menggunakan ukuran keuangan sebagaimana halnya dalam sistem pengukuran kinerja tradisional, pengukuran kinerja balanced scorecard juga menggunakan perspektif non keuangan, seperti: perspektif pelanggan, perspektif proses bisnis intern, dan perspektif pembelajaran dan pertumbuhan. Informasi keuangan untuk mengukur kinerja keuangan perusahaan. Ukuran kinerja keuangan yang dipakai adalah profitabilitas, yang diartikan sebagai kemampuan perusahaan dalam menghasilkan laba. Adapun alasan menggunakan ukuran kinerja profitabilitas adalah: (1) Profitabilitas merupakan ukuran kinerja keuangan penting dan sering digunakan untuk mengukur kinerja keuangan secara keseluruhan dan dapat mengukur tingkat efisiensi dalam pengelolaan aset, kewajiban, dan ekuitas perusahaan tergantung pada tingkat keuntungan yang diperoleh dan penerimaan dividen dimasa yang akan datang.

\section{PUSTAKA ACUAN}

Burton, F. G., Chen, Y., Grover, V., and Steward, K.A. 1992. An Application of Expectancy Theory for Assesing User Motivation to Utilize an Expert System. Journal of Management Information System. 9 (3): 183-198.

Cerullo, M.J. 1997. Information Systems Success Factors. Journal of Systems Management. 31(12): 10-19.

Cho, D.Y., and Kwon, D. 2005. Self-Directing Learning Readiness as an Antecedent of Organizational Commitmen: a Korean Study. International Journal of Training and Development. 9(2): 140-152.

Choe, J.M. 1996. The Relationship Among Performance of Accounting Information System, Influence Factors, and Evolution Level of Information System. Journal of Management Information System. 12(4): 215-239.

Clercq, D.D., and Dimov, D. 2008. Internal Knowlwdge Development and External Knowledge Access in Venture Capital Investment Performance. Journal of Management Studies. 45(3): 585-612.

Chen, Z.X., Tsui, A.S., and Farh, J.L. 2002. Loyality to Supervisors vs. Organizational Commitment: Relationships to Employee performance in China. Journal of Occupational and Organizational Psychology. 75: 339-356.

Clercq, D.D., and Rius, I.B. 2007. Organizational Commitment in Mexican Small and MediumSized Firms: The Role of Work Status, Organizational Climate, and Entrepreneurial Orientation. Journal of Small Business Management. 10(2): 185-210.

Gelinas, J.U., Allan, O.E., and William, W.P. 1993. Accounting Information System. Second Edition, Cincinnati, Ohio: South-Western Publishing Co.

Essex, P.A., Magal, S.R. and Mateller, D.E. 1998. Determinan of Information Center Success. Journal of Management Information System. 15(2): 95-117.

Etty Murwaningsari. 2008. The Role of Organizational Commitment and Procedural Justice in Moderating the Relationship Between Budgetary Participation and Managerial Performance. Gadjah Mada International Journal of Business. 10(2): 185-210. 
Faisal Basri. 2002. Perekonomian Indonesia: Tantangan dan Harapan Bagi Kebangkitan Indonesia. Jakarta: Erlangga

Gibson, C.H. 1992. Financial Statement Analysis Using Financial Accounting Information. Fifth Editon. USA: South-Western Publishing Campany.

Gibson, J.L., Invancevich, J.M., and Donnelly, J.M. 1994. Organization Behavior: Structure and Process. Seventh Edition, Boston: Homewood, Richard D. Irwin.

Haar, J.M., and Spell, C.S. 2004. Programme Knowledge and Value pf Work-Family Practices and Organizational Commitment. The International Journal of Human Resource Management. 15(6): 1040-1055

Hair, F., Joseph, R.E., Anderson, Ronal, L.T., and William C.B. 2014. Multivariat Data Analysis. $9^{\text {th }}$ Edition. Prentice Hall International Inc.

Hertati.L. 2015. Total Quality Management As Technics on Strategic Management Accounting. International Journal of Recent Advances in Multidisciplinary Research Vol. 02, Issue 11, pp.0942-0949, November, 2015

Hertati, L.2015. Internal Control And Ethics Of Quality Management Accounting Information Systems And Implications On The Quality Of Accounting Information Management: Proposing A Research Framework. International Journal of Economics, Commerce and Management United Kingdom Vol. III, Issue 6, June 2015 Licensed under Creative Common Page 902 http://ijecm.co.uk/ ISSN 23480386

Hertati.L. 2016. Just In Time, Value Chain, Total Quality Management, Part Of Technical Strategic Management Accounting. International Journal of Scientific \& Technology Research Volume 5, Issue 04, April 2016 Issn 2277-8616

Hertati, and Sumantri 2016. Just In Time, Value Chain, Total Quality Management, Part Of Technical Strategic Management Accounting.International Journal Of Scientific \& Technology Research Volume 5, Issue 04, April 2016 Issn 2277-8616.

Hertati.L. et, all 2019. The Effect of Human Resource Ethics on Financial Reporting Implications for Good Government Governance (Survey of Related Sub-units in Stateowned Enterprises in SUMSEL). International Journal of Economics and Financial Issues ISSN: 2146-4138 available at http: www.econjournals.com International Journal of Economics and Financial Issues, 2019, 9(4), 267-276

Imam Ghozali, dan Fuad. 2005. Struktural Equation Modeling, Teori, Konsep, dan Aplikasi dengan Program Lisrel 8.54. Semarang: Penerbit Undip

Kaplan, R.S., and Norton, D.P. 1996. The Balanced Scorecard: Translating Strategy into Action. Boston, Massachusetts: Harvard Business School Press.

Kaye, G.R. 1990. Information System Successes and Failures: Research Finding from the Compunding Industry. Jurnal of Information Technology. 5: 73-83.

Larsen, K.R.T. 2003. A Taxonomy of Antecedents of Information Systems Implementation: Variable Analysis Studies. Journal of Management Information Systems. 20(2): 169-246.

Lee, J.J., and Kim, S.H. 1992. The Relationship Between Procedural Formalization in MIS Development and MIS Success. Information and Management, 22(2): 89-111.

Livari, J. 2005. An Empirical Test of The Delone-McLean Model of Information System 
Success. Database for Advance in Information System (DFA). ISSN: 1532-0936. Volume 36. ProQuest Company.

Mcshane, Steven L., and Von Glinow, M.A. 2000. Organizational Behavior. USA: McGraw-Hill Companies, Inc.

Mowday, R.T., Porter, L.W., and Steers, R.M. 1982. Employee-Organization Linkages. New York: Academic Press.

Neely, A., Gregory, M.J., and Platts, K.W. 1995. Performance Measurement System Design - A Literature Review and Research Agenda. International Journal of Operation and Production Management. 14(3): 140-152.

Rayner, R.K., and Watson, H.J. 1995. The Keys to Executive Information System Success. Journal of Management Information System. 12(2): 83-98.

Romney, B.M., and Steinbart, J.P. 2009. Accounting Information System. Eleventh Edition. USA: Pearson Prentice Hall.

Saunders, C.S., and Jones, J.W. 1992. Measuring Performance of the Information Systems Function. Journal of Management Information System. 8(4): 63-82.

Sabherwal, R., Jeyaraj, A., and Chowa C. 2006. Information System Success: Individual and Organizational Determinants. Management Science. 52(12): 1849-1864

Shirani, et.al. 1994. A Model of User Information Satisfaction. Data Base. 25(4): 17-23.

Susanto,A.2014. Sistem informasi Akuntansi: Struktur Pengendalian Resiko Pengembangan. Edisi Perdana. Bandung: Lingga Jaya.

Sofyan Djalil. 2008. Peranan BUMN Untuk Menggerakkan Sektor Riil Dalam Situasi Krisis Global. Melalui <http://www.bumn.go.id> [22/09/09].

Straub, et.al. 1995. Measuring System Usage: Implications for IS Theory Testing. Management Science, 41(8): 1328-1342.

Thong, J.Y.T., and Yap, C. 1996. Information Systems Effectiveness: A User Satisfaction Approach. Information Processing \& Management. 32(5): 601-610

Torkzadeh G., and Doll, W.J. 1998. The Test-Retest Reliability of User Involvement Instruments. Information and Management. 26(1): 21-31.

Mulyani.S 2010. Menkeu Kritik Laporan Keuangan BUMN. Melalui <http://www.republika. co.id> [10/07/10].

Yuksel, H. 2004. An Empirical Evaluation of Problem in Performance Measurement System of Big Sized Firms in Turkey. Working paper. Second World Conference on POM and $15^{\text {th }}$ Annual POM Conference. Caucun Mexico April 30-May 3.

Zhang, M.J. 2005. Information Systems, Strategic Flexibility and Firm Performance: An Empirical Investigation. Journal of Engineering and Technology Management. 22: 163-184.

Zhang. 2007a. Information Systems (IS) Connectivity as a Moderator of the Effects of IS Support for Information Interpretation on Firm Performance: An Empirical Study. International Journal of Management. 24(2): 263-275.

Zhang. 2007b. Assessing the Performance Impact of Information System from the ResourceBased Perspective: An Emperical Test of the Indirect Effect of IS. Journal of Business Strategies, 24(2): 141-164. 